\title{
Paediatric patients as a COVID-19 transmitter
}

\section{To the Editor,}

The role of paediatric patients in transmitting the disease to others is unknown, especially given the unknown number of asymptomatic cases. Most children infected with COVID-19 are asymptomatic or have mild symptoms such as coughing, fever or chills, breathlessness or respiratory problems, muscle or body pain, sore throat, loss of taste or smell, diarrhoea, headache, fatigue, nausea or vomiting, nasal congestion or rhinitis. Of the many of these symptoms, if individual symptoms occur, they may go unnoticed by the parent. Children now account for $10.6 \%$ of all infected children, of whom $1.8 \%$ required hospitalization and did not have a severe covid-19 infection, their mortality rate is low and remains $0.06 \%$ of all deaths and $0.02 \%$ of the deaths of infected children, as shown by data collected from the AAP in the United States [1]. Recently, there have also been reports about the duration of the infection in children infected with covid-19, who may be infected for up to 6 weeks, which could suggest an easy possibility of infecting others while in contact with them [2]. There were also reports of persistent amounts of virus nucleic acid in the nasopharynx in individual age groups, of which small children under 5 years of age have equivalent or higher levels of viral nucleic acid in the upper respiratory tract, compared to older children and adults. Although this study was limited to the detection of viral nucleic acid and not the infectious virus, studies conducted on children with covid-19 infection showed a correlation between higher levels of nucleic acids and the ability to grow an infectious virus [3].
The study also showed that SARS-CoV-2 clearance in the airways occurred within two weeks after the fever disappeared, while viral RNAs remained detectable in the stool of paediatric patients for more than 4 weeks, which could suggest the possibility of infection through contact with children who were theoretically cured [4]. The asymptomatic or very mild COVID-19 transmission by paediatric patients, the long duration of the infection, as well as the amount of infectious material, suggests that children can spread the virus very easily in society.

In summary, in many countries, small children are not required to wear personal protective equipment such as masks, which may expose people around them to infection. Infections in paediatric patients should be further explored, and preventive measures are taken to reduce the infections involving them.

\section{References}

1. Children and COVID-19: State Data Report A joint report from the American Academy of Pediatrics and the Children's Hospital Association Summary of publicly reported data from 49 states, NYC, DC PR, and GU Version: 10/1/20

2. Sola AM, David AP, Rosbe KW, et al. Prevalence of SARS-CoV-2 Infection in Children Without Symptoms of Coronavirus Disease 2019. JAMA Pediatr. 2020 [Epub ahead of print], doi: 10.1001/jamapediatrics.2020.4095, indexed in Pubmed: 32840605.

3. Heald-Sargent T, Muller WJ, Zheng X, et al. Age-Related Differences in Nasopharyngeal Severe Acute Respiratory Syndrome Coronavirus 2 (SARS-CoV-2) Levels in Patients With Mild to Moderate Coronavirus Disease 2019 (COVID-19). JAMA Pediatr. 2020; 174(9): 902-903, doi: 10.1001/jamapediatrics.2020.3651, indexed in Pubmed: 32745201.

4. Xing $\mathrm{YH}, \mathrm{Ni} W, \mathrm{Wu} \mathrm{Q}$, et al. Prolonged viral shedding in feces of pediatric patients with coronavirus disease 2019. J Microbiol Immunol Infect. 2020; 53(3): 473-480, doi: 10.1016/j.jmii.2020.03.021, indexed in Pubmed: 32276848 